\title{
Hydroxychloroquine prescription trends and predictors for excess dosing per recent ophthalmology guidelines
}

\author{
April M. Jorge ${ }^{1 *}$ D, Ronald B. Melles², Yuqing Zhang1', Na Lu', Sharan K. Rai', Lucy H. Young ${ }^{3}$, \\ Karen H. Costenbader ${ }^{4}$, Rosalind Ramsey-Goldman ${ }^{5}$, S. Sam Lim', John M. Esdaile', Ann E. Clarke ${ }^{8}$, M. B. Urowitz ${ }^{9}$, \\ Anca Askanase $^{10}$, Cynthia Aranow ${ }^{11}$, Michelle Petri ${ }^{12}$ and Hyon Choi ${ }^{1}$
}

\begin{abstract}
Background: Hydroxychloroquine (HCQ) retinopathy may be more common than previously recognized; recent ophthalmology guidelines have revised recommendations from ideal body weight (IBW)-based dosing to actual body weight (ABW)-based dosing. However, contemporary HCQ prescribing trends in the UK remain unknown.

Methods: We examined a UK general population database to investigate HCQ dosing between 2007 and 2016. We studied trends of excess HCQ dosing per ophthalmology guidelines (defined by exceeding $6.5 \mathrm{mg} / \mathrm{kg}$ of IBW and $5.0 \mathrm{mg} / \mathrm{kg}$ of $\mathrm{ABW}$ ) and determined their independent predictors using multivariable logistic regression analyses.

Results: Among 20,933 new HCQ users (78\% female), the proportions of initial HCQ excess dosing declined from $40 \%$ to 36\% using IBW and 38\% to 30\% using ABW, between 2007 and 2016. Among these, 47\% of women were excess-dosed (multivariable OR 12.52; 95\% Cl 10.99-14.26) using IBW and 38\% (multivariable OR 1.98; 95\% Cl,1.81-2.15) using ABW. Applying IBW, 37\% of normal and 44\% of obese patients were excessdosed; however, applying ABW, 53\% of normal and 10\% of obese patients were excess-dosed (multivariable ORs $=1.61$ and 0.1 (reference $=$ normal); both $p<0.01$ ). Long-term HCQ users showed similar excess dosing.

Conclusion: A substantial proportion of HCQ users in the UK, particularly women, may have excess HCQ dosing per the previous or recent weight-based guidelines despite a modest decline in recent years. Over half of normal-BMI individuals were excess-dosed per the latest guidelines. This implies the potential need to reduce dosing for many patients but also calls for further research to establish unifying evidence-based safe and effective dosing strategies.
\end{abstract}

Keywords: DMARDs, Epidemiology, Quality of care, Rheumatoid arthritis, Systemic lupus erythematosus

\section{Background}

Hydroxychloroquine (HCQ) is commonly prescribed in patients with systemic lupus erythematosus (SLE) and remains a cornerstone of lupus care today $[1,2]$, and it is also often used in the management of rheumatoid arthritis (RA) and other rheumatic conditions. Since the landmark trial that showed HCQ discontinuation led to

\footnotetext{
* Correspondence: AMJorge@mgh.harvard.edu

'Division of Rheumatology, Allergy, and Immunology, Department of Medicine, Massachusetts General Hospital, Harvard Medical School, 55 Fruit Street, Bulfinch 165, Boston, MA 02114, USA

Full list of author information is available at the end of the article
}

a nearly threefold higher risk of lupus exacerbation [3], many subsequent studies have reported wide-ranging benefits of $\mathrm{HCQ}$, including improved survival, reduced disease activity and damage accumulation, and a lower risk of pregnancy complications, venous thromboembolism, dyslipidemia, and insulin resistance among patients with SLE [4-7]. In RA, the efficacy of triple therapy (which includes HCQ) is proven to be similar to that of etanercept [8], while being much more cost-effective [9]. This profile will likely remain attractive worldwide, even in the era of modern biologic agents.

(c) The Author(s). 2018 Open Access This article is distributed under the terms of the Creative Commons Attribution 4.0 International License (http://creativecommons.org/licenses/by/4.0/), which permits unrestricted use, distribution, and reproduction in any medium, provided you give appropriate credit to the original author(s) and the source, provide a link to the Creative Commons license, and indicate if changes were made. The Creative Commons Public Domain Dedication waiver (http://creativecommons.org/publicdomain/zero/1.0/) applies to the data made available in this article, unless otherwise stated. 
Although HCQ is generally well-tolerated, the major long-term adverse event is vision-threatening toxic retinopathy $[10,11]$. Rates of HCQ retinopathy were historically considered low $(<2 \%)$ [12-15]. Previously, the 2009 Royal College of Ophthalmologists (RCO) and 2011 American Academy of Ophthalmology (AAO) guidelines each recommended a maximum safe dose of $6.5 \mathrm{mg} / \mathrm{kg} /$ day of ideal body weight (IBW) (up to a maximum of $400 \mathrm{mg}$ daily) to minimize the risk of retinopathy $[2,16,17]$. However, in 2016, the AAO updated their maximum daily dose recommendation to $5 \mathrm{mg} / \mathrm{kg} /$ day actual body weight (ABW), based largely on a retrospective study based in Kaiser Permanente Northern California (KPNC) [18-20]. This study utilized modern, sensitive screening methods that can identify early stages of retinopathy and identified an overall prevalence of HCQ retinopathy of $7.5 \%$, over three times higher than previous estimates [14, 21, 22]. The rate of retinopathy was considerably higher with HCQ doses over $5.0 \mathrm{mg} / \mathrm{kg}$ ABW [18]. Following the KPNC study, there has been renewed concern in the USA about the appropriate dosing of $\mathrm{HCQ}$, reflected in the latest $\mathrm{AAO}$ guidelines $[15,19,23,24]$. Despite the previous IBW-based recommendation [16], there may have been less concern about HCQ retinopathy in the UK than in the USA, as the RCO had not recommended routine HCQ retinopathy screening prior to 2017 [16, 25-27]. To that end, to what extent recent HCQ prescriptions would exceed dosing recommended by ophthalmology guidelines remain unknown.

To understand recent prescribing trends in the UK and to elucidate the predictors of potential excess dosing, we assessed HCQ prescribing patterns in relation to the previous and latest $\mathrm{HCQ}$ dosing guidelines $[16,17$, 20,26 ] over a recent 10 -year period in a UK general population database.

\section{Methods}

\section{Data source}

Our study cohort was derived from The Health Improvement Network (THIN), an electronic medical record (EMR) database which represents $6.2 \%$ of the UK population, including over 11 million patients. THIN database is representative of the general UK population in terms of demographics, lifestyle factors, and healthcare utilization [28]. Healthcare information includes general practitioner visits, specialist referrals, diagnoses from hospital admissions and specialists, medications, and laboratory results. The specific diagnoses are recorded by the Read code classification system, which is the standard nomenclature of clinical terms used by the National Health Service in describing clinical diagnoses [29]. Medication prescriptions are recorded by the Multifunctional Standardized Lexicon for European Community Language (MULTILEX) classification system [30].

\section{Study population and design}

We identified all subjects age 18 years or older within THIN with incident HCQ prescriptions between 1 January 2007 and 31 December 2016. We divided these cohorts into five 2-year blocks each, based on index date, determined by the date of first documented HCQ prescription. We required $\geq 1$ year of subject inclusion in THIN prior to the index date to be considered an incident prescription.

\section{Assessment of covariates}

We determined information from the most recent available data prior to the index date on age, sex, lifestyle (i.e., smoking), and anthropometric characteristics (i.e., height and body weight). We calculated body mass index (BMI) and IBW using the commonly used Devine formula (for women, $45.5 \mathrm{~kg}+2.3 \times$ height in inches over $60 \mathrm{in}$. and for men, $50 \mathrm{~kg}+2.3 \times$ height in inches over 60 in.) [30, 31], as was also used in the recent KPNC paper [18]. We identified the indication for HCQ use by Read diagnosis codes. We also determined baseline comorbidities (i.e., diabetes mellitus and chronic kidney disease (CKD) stage $\geq 3$ ) and medication use (i.e., tamoxifen, which has been previously implicated in increased risk of HCQ retinopathy) [18].

\section{Assessment of outcomes}

We identified the incident HCQ prescription dose for the primary analysis. We also obtained overall (incident and renewal prescriptions) HCQ prescription dose, assessing the first prescription dose in a given calendar year for each subject. We classified the weight-based excess HCQ dose according to recommended safe doses per IBW (i.e., $>6.5 \mathrm{mg} / \mathrm{kg}$ ) [16, 27], and per ABW (i.e., $>5.0 \mathrm{mg} / \mathrm{kg}$ ) $[18,19]$. We also examined HCQ daily dose categories (i.e., $100 \mathrm{mg}, 200 \mathrm{mg}, 300 \mathrm{mg}, 400 \mathrm{mg}$, $500 \mathrm{mg}$, and $600 \mathrm{mg}$ ), rounding to the nearest $100 \mathrm{mg}$ (or one half tablet) per day, given that this medication is only available in $200 \mathrm{mg}$ tablets.

To examine the dosing trends according to the duration of use, we obtained the initial HCQ prescription dose and the HCQ prescription dose at 5 years of treatment for a subgroup of subjects with at least 5 years of HCQ use. We similarly classified their 1 st and 5 th year prescription doses according to recommended doses per ABW and IBW.

\section{Statistical analysis}

We compared the baseline characteristics of individuals at the index date of their incident HCQ prescriptions according to calendar year categories. We calculated the proportion of incident HCQ prescriptions exceeding either IBW or ABW maximum safe dose over the five 2-year cohort blocks and described the secular trends. 
We examined the relationship between age, sex, BMI, CKD, and indication for HCQ use and the risk of prescribed HCQ dose exceeding each safe dose for IBW or ABW, respectively, using a multivariable logistic regression model. The final multivariable model was adjusted for age, sex, BMI, CKD, indication for HCQ use, smoking, tamoxifen use, diabetes mellitus, and calendar year.

We calculated median and interquartile ranges for initial HCQ dose per IBW and ABW at 6-month intervals between 2007 and 2016 and performed quantile regression to assess the median value trends. Furthermore, we calculated the proportion of different HCQ dose categories (i.e., $600 \mathrm{mg}, 500 \mathrm{mg}, 400 \mathrm{mg}, 300 \mathrm{mg}, 200 \mathrm{mg}$, and $100 \mathrm{mg}$ ) comprising overall initial HCQ doses over this same timeframe. We also calculated the proportion of these dose categories comprising overall (incident and renewal) HCQ doses over this timeframe.

\section{Results}

During the 10-year period between 2007 and 2016, 20,933 individuals initiated HCQ (Table 1). The majority were female (78\%). The mean age was 55.6 years and mean BMI was $27.7 \mathrm{~kg} / \mathrm{m}^{2}$. RA was the most common indication for HCQ use (56\%), 2257 subjects (11\%) had SLE, and 1572 (8\%) had CKD $\geq$ stage 3.
Between 2007 and 2016, proportions of initial HCQ excess dosing declined from $40 \%$ to $36 \%$ per IBW-based dosing (multivariable OR between 2007 and 2008 and between 2015 and 2016, 0.85 (95\% CI 0.76-0.95)) and from $38 \%$ to $30 \%$ per ABW-based dosing (multivariable OR, 0.76 (95\% CI 0.68-0.86)) (Table 2). Correspondingly, the median HCQ dose per IBW declined from $6.0 \mathrm{mg} / \mathrm{kg}$ to $5.7 \mathrm{mg} / \mathrm{kg}$ during the study period, and the median HCQ dose per ABW declined from $4.4 \mathrm{mg} / \mathrm{kg}$ to $4.1 \mathrm{mg} / \mathrm{kg}$ (both $p$ values < 0.01) (Fig. 1). Furthermore, the proportions of initial prescribed daily dose categories of HCQ changed over time, with a slightly lower proportion of $400 \mathrm{mg}$ per day prescribed in recent years and an increase in the relative proportions of $100 \mathrm{mg}, 300 \mathrm{mg}$, and $500 \mathrm{mg}$ doses, as shown in Fig. 2. These trends remain similar in our analyses that include subsequent doses after initial doses (Additional file 1: Figure S1). Furthermore, when we limited our analyses to those with body weight measured within 1 year prior to index date, our result did not change materially.

Using IBW-based recommended dose, $47 \%$ of women and $7 \%$ of men had excess dosing, which resulted in a multivariable OR of 12.52 (95\% CI, 10.99-14.26). Using the ABW-based recommended dose, $38 \%$ of women and $25 \%$ of men had excess dosing, which led to a multivariable OR of 1.98 (95\% CI, 1.81-2.15) (Table 2). Age group

Table 1 Baseline characteristics of hydroxychloroquine incident users by time period

\begin{tabular}{|c|c|c|c|c|c|c|}
\hline \multirow{3}{*}{ Characteristics } & \multicolumn{5}{|c|}{ Time period of initial prescription } & \multirow{3}{*}{$\begin{array}{l}\text { All } \\
(n=20,933)\end{array}$} \\
\hline & $2007-2008$ & $2009-2010$ & $2011-2012$ & $2013-2014$ & $2015-2016$ & \\
\hline & $(n=3297)$ & $(n=4151)$ & $(n=4927)$ & $(n=4944)$ & $(n=3614)$ & \\
\hline Sex (\% female) & $2617(79)$ & $3267(79)$ & $3822(79)$ & $3846(78)$ & $2751(76)$ & $16,303(78)$ \\
\hline Mean age, years (SD) & $53.7(15)$ & $54.9(15)$ & $55.7(15)$ & $56.2(15)$ & $56.9(15)$ & $55.6(15)$ \\
\hline $\mathrm{BMI}, \mathrm{kg} / \mathrm{m}^{2}$ (mean +/- SD) & $27.3(6)$ & $27.4(6)$ & $27.6(6)$ & $27.8(6)$ & $28.4(6)$ & $27.7(6)$ \\
\hline \multicolumn{7}{|l|}{ BMI category (\%) } \\
\hline Underweight (BMI < 18.5) & $81(3)$ & $89(2)$ & $95(2)$ & $90(2)$ & $68(2)$ & $424(2)$ \\
\hline Normal (BMI $18.5-<25$ ) & $1096(37)$ & $1371(36)$ & $1623(36)$ & $1553(34)$ & $1054(31)$ & $6697(35)$ \\
\hline Overweight (BMI $25-<30$ ) & $942(32)$ & $1274(34)$ & $1530(34)$ & $1527(34)$ & 1139 (33) & $6412(33)$ \\
\hline Obese (BMI 30+) & $815(28)$ & $1053(28)$ & $1271(28)$ & $1390(31)$ & $1157(34)$ & $5686(30)$ \\
\hline CKD ( $\geq$ stage 3 ) & $213(7)$ & $344(8)$ & $366(7)$ & $366(7)$ & $283(8)$ & $1572(8)$ \\
\hline Tamoxifen use & $26(1)$ & $47(1)$ & $66(1)$ & $69(1)$ & $54(2)$ & $262(1)$ \\
\hline Diabetes mellitus (\%) & $228(7)$ & $370(9)$ & $483(10)$ & $552(11)$ & $517(14)$ & $2150(10)$ \\
\hline Smoking status (\% current smoker) & $696(22)$ & $881(22)$ & $977(20)$ & $953(20)$ & $645(18)$ & $4152(20)$ \\
\hline \multicolumn{7}{|l|}{ Indication for HCQ (\%) } \\
\hline RA/inflammatory arthritis & $1745(53)$ & $2352(57)$ & $2794(57)$ & $2863(58)$ & $2001(56)$ & $11,749(56)$ \\
\hline SLE & $459(14)$ & $462(11)$ & $481(10)$ & $415(8)$ & $283(8)$ & $2100(10)$ \\
\hline Systemic autoimmune rheumatic disease ${ }^{a}$ & $117(4)$ & $156(4)$ & $183(4)$ & $174(4)$ & $148(4)$ & $778(4)$ \\
\hline Primary dermatologic disease & $282(9)$ & $384(9)$ & $489(10)$ & $5142(11)$ & 486 (13) & $2183(10)$ \\
\hline All other indications & $700(21)$ & 797 (19) & $980(20)$ & $950(19)$ & 696 (19) & $4123(20)$ \\
\hline
\end{tabular}

$B M I$ body mass index, CKD chronic kidney disease, HCQ hydroxychloroquine, SLE systemic lupus erythematosus, RA rheumatoid arthritis

${ }^{\text {a }}$ Systemic autoimmune rheumatic disease category excludes SLE and RA 
Table 2 Initial hydroxychloroquine prescription dose in relation to dosing recommendations

\begin{tabular}{|c|c|c|c|c|c|c|}
\hline \multirow[t]{2}{*}{ Characteristics } & \multicolumn{3}{|c|}{$\begin{array}{l}\text { Dose }>6.5 \mathrm{mg} / \mathrm{kg} / \mathrm{day} \text {, ideal body weight (prior } \\
\text { recommendation) }\end{array}$} & \multicolumn{3}{|c|}{$\begin{array}{l}\text { Dose }>5 \mathrm{mg} / \mathrm{kg} / \text { day, actual body weight (latest } \\
\text { recommendation) }\end{array}$} \\
\hline & Number (\%) & $\begin{array}{l}\text { Crude OR } \\
(95 \% \mathrm{Cl})\end{array}$ & $\begin{array}{l}\text { Multivariable } \\
\text { OR }(95 \% \mathrm{Cl})\end{array}$ & Number (\%) & $\begin{array}{l}\text { Crude OR } \\
(95 \% \mathrm{Cl})\end{array}$ & $\begin{array}{l}\text { Multivariable } \text { OP } \\
(95 \% \mathrm{Cl})\end{array}$ \\
\hline \multicolumn{7}{|l|}{ Year of initial prescript } \\
\hline $2007-2008$ & $1099(40)$ & 1.00 (Reference) & 1.00 (Reference) & 1055 (38) & 1.00 (Reference) & 1.00 (Reference) \\
\hline 2009-2010 & $1406(39)$ & $0.98(0.88-1.08)$ & $1.00(0.89-1.11)$ & $1348(38)$ & $0.97(0.88-1.08)$ & $0.99(0.89-1.11)$ \\
\hline $2011-2012$ & $1597(38)$ & $0.920 .83-1.02)$ & $0.95(0.85-1.05)$ & $1519(36)$ & $0.91(0.82-1.00)$ & $0.920 .83-1.03)$ \\
\hline 2013-2014 & $1511(37)$ & $0.88(0.80-0.97)$ & $0.90(0.76-1.00)$ & $1408(35)$ & $0.84(0.76-0.93)$ & $0.88(0.79-0.99)$ \\
\hline 2015-2016 & $1073(36)$ & $0.84(0.76-0.94)$ & $0.85(0.76-0.95)$ & $901(30)$ & $0.70(0.62-0.78)$ & $0.76(0.68-0.86)$ \\
\hline \multicolumn{7}{|l|}{ Sex } \\
\hline Male & $268(7)$ & 1.00 (Reference) & 1.00 (Reference) & $998(25)$ & 1.00 (Reference) & 1.00 (Reference) \\
\hline Female & $6418(47)$ & $11.71(10.30-13.32)$ & 12.52 (10.99-14.26) & $5233(38)$ & $1.76(1.62-1.90)$ & $1.98(1.81-2.15)$ \\
\hline \multicolumn{7}{|l|}{ Age } \\
\hline$\leq 55$ years & 3647 (38) & 1.00 (Reference) & 1.00 (Reference) & $3453(36)$ & 1.00 (Reference) & 1.00 (Reference) \\
\hline$>55$ years & 3039 (38) & $1.00(0.94-1.08)$ & $1.23(1.15-1.32)$ & $2778(35)$ & $0.95(0.89-1.01)$ & $1.18(1.10-1.27)$ \\
\hline \multicolumn{7}{|l|}{ BMI $\left(\mathrm{kg} / \mathrm{m}^{2}\right)$} \\
\hline Underweight $(<18.5)$ & $104(28)$ & $0.74(0.59-0.93)$ & $0.66(0.52-0.84)$ & $176(48)$ & $0.82(0.66-1.01)$ & $0.78(0.63-0.97)$ \\
\hline Normal $(18.5-<25)$ & $2114(35)$ & 1.00 (Reference) & 1.00 (Reference) & $3215(53)$ & 1.00 (Reference) & 1.00 (Reference) \\
\hline Overweight $(25-<30)$ & $2134(36)$ & $1.07(1.00-1.12)$ & $1.28(1.19-1.39)$ & 2319 (39) & $0.58(0.54-0.63)$ & $0.61(0.57-0.66)$ \\
\hline Obese $(\geq 30)$ & $2334(44)$ & $1.51(1.40-1.63)$ & $1.61(1.49-1.75)$ & $521(10)$ & $0.10(0.09-0.11)$ & $0.10(0.09-0.11)$ \\
\hline \multicolumn{7}{|l|}{ Smoking } \\
\hline Current smoker & $1245(36)$ & $0.89(0.83-0.96)$ & $1.06(0.98-1.16)$ & $1294(37)$ & $1.10(1.02-1.19)$ & $1.03(0.95-1.13)$ \\
\hline Non-smoker & $5426(39)$ & 1.00 (Reference) & 1.00 (Reference) & $4924(35)$ & 1.00 (Reference) & 1.00 (Reference) \\
\hline \multicolumn{7}{|l|}{ CKD } \\
\hline CKD stage $>3$ & $516(37)$ & $0.97(0.86-1.08)$ & $0.88(0.73-1.00)$ & $429(31)$ & $0.81(0.72-0.91)$ & $0.87(0.76-0.99)$ \\
\hline No CKD & $6170(38.1)$ & 1.00 (Reference) & 1.00 (Reference) & $5802(36)$ & 1.00 (Reference) & 1.00 (Reference) \\
\hline \multicolumn{7}{|l|}{ Diabetes } \\
\hline Yes & $726(38)$ & $0.99(0.90-1.09)$ & $1.05(0.94-1.17)$ & $483(25)$ & $0.58(0.52-0.65)$ & $0.92(0.81-1.03)$ \\
\hline No & $5960(38)$ & 1.00 (Reference) & 1.00 (Reference) & $5748(37)$ & 1.00 (Reference) & 1.00 (Reference) \\
\hline \multicolumn{7}{|l|}{ Tamoxifen use } \\
\hline Yes & $113(51)$ & $1.67(1.29-2.18)$ & $1.16(0.89-1.52)$ & $94(42)$ & $1.32(1.01-1.73)$ & $1.16(0.87-1.55)$ \\
\hline No & $6573(38)$ & 1.00 (Reference) & 1.00 (Reference) & $6137(35)$ & 1.00 (Reference) & 1.00 (Reference) \\
\hline \multicolumn{7}{|l|}{ Indication for HCQ } \\
\hline RA/inflammatory arthritis & $3651(36)$ & 1.00 (Reference) & 1.00 (Reference) & $3491(35)$ & 1.00 (Reference) & 1.00 (Reference) \\
\hline SLE & $628(37)$ & $1.03(0.93-1.15)$ & $0.84(0.75-0.94)$ & $590(35)$ & $1.04(0.93-1.17)$ & $0.87(0.77-0.98)$ \\
\hline SARD & $287(43)$ & $1.34(1.14-1.56)$ & $1.07(0.91-1.26)$ & $272(41)$ & $1.29(1.10-1.51)$ & $1.09(0.92-1.30)$ \\
\hline Primary dermatologic disease & $745(41)$ & $1.23(1.11-1.36)$ & $1.11(0.99-1.25)$ & $655(36)$ & $1.04(0.95-1.15)$ & $1.12(0.99-1.26)$ \\
\hline Other & $1375(41)$ & $1.24(1.14-1.34)$ & $1.16(1.06-1.27)$ & $1223(37)$ & $1.10(1.01-1.19)$ & $1.14(1.04-1.25)$ \\
\hline
\end{tabular}

BMI body mass index, CKD chronic kidney disease, SLE systemic lupus erythematosus, RA rheumatoid arthritis, SARD systemic autoimmune rheumatic disease ${ }^{a}$ Multivariable odds ratios are adjusted for age, sex, BMI, CKD, indication for hydroxychloroquine use, smoking, tamoxifen use, diabetes mellitus, and calendar year

was not associated with the risk of excess dosing in crude comparison (Table 2); however, our sequential adjustment of covariates in our model revealed that this null association was confounded by the predominant presence of young women among HCQ users. As such, when our model was adjusted for female sex, older patients were more likely to be prescribed HCQ doses exceeding either recommendation in the adjusted models (multivariable OR 1.23 (95\% CI 1.15-1.32) for IBW and multivariable OR 1.18 (95\% CI 1.10-1.27) for ABW) (Table 2).

Proportions of initial HCQ excess dosing per the IBW-based recommendation increased with increasing 


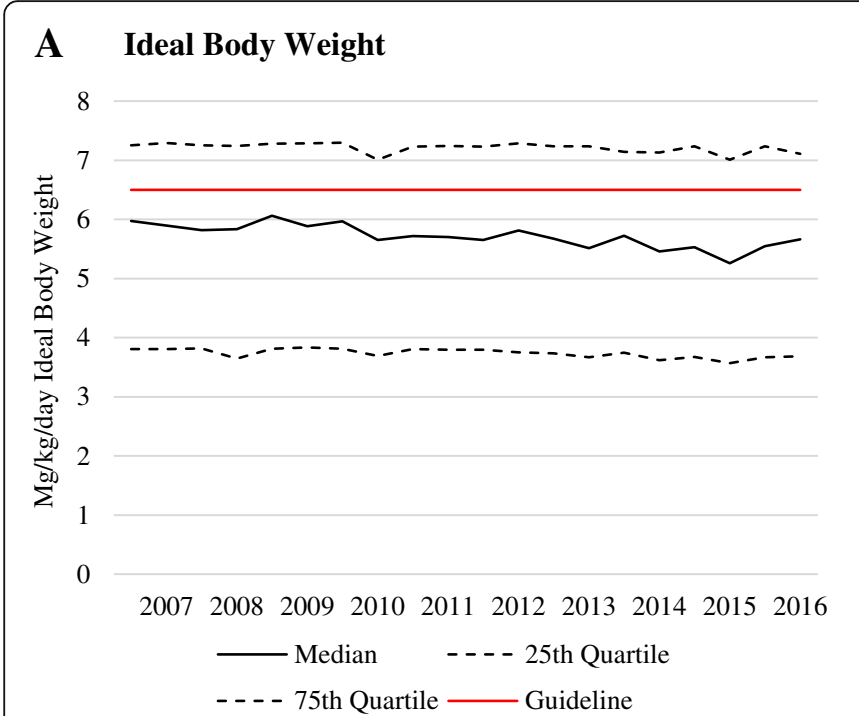

\section{B Actual Body Weight}

8

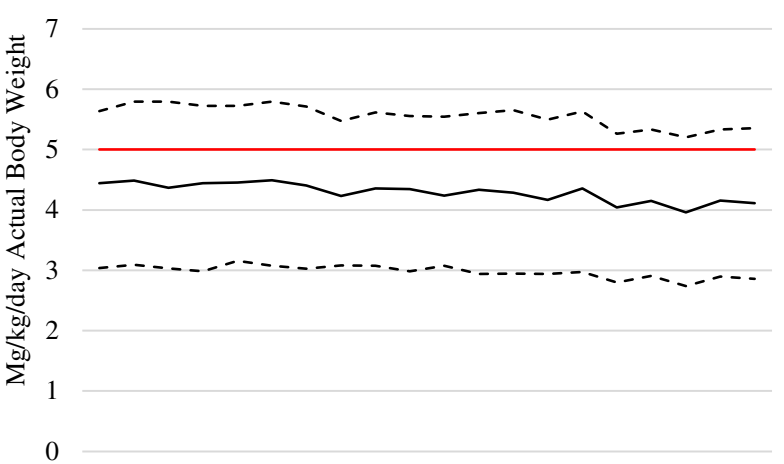

2007200820092010201120122013201420152016

- Median - - - - 25th Quartile

Fig. 1 Trends of incident hydroxychloroquine prescription dose per ideal body weight and actual body weight (2007-2016). Median and inter-quartile ranges of incident hydroxychloroquine prescription dose, calculated per mg/kg of ideal body weight and per mg/kg of actual body weight, in relation to published guideline-recommendations

BMI (28\%, 35\%, 36\%, and 44\% in underweight, normal, overweight, and obese categories, respectively) (Table 2). These resulted in a multivariable OR of 1.61 (95\% CI 1.49-1.75) for obese individuals versus individuals with normal BMI (Table 2). In contrast, proportions of initial HCQ excess dosing per ABW-based recommendation decreased with increasing BMI (48\%, 53\%, 39\%, and $10 \%$, in underweight, normal, overweight, and obese categories, respectively). These resulted in a multivariable OR of 0.10 (95\% CI 0.09-0.11) among obese individuals versus individuals with normal BMI. Patients with CKD had a lower risk of excess dosing by IBW (OR 0.88 (95\% CI 0.73-1.00)) and by ABW (OR 0.87 (95\% CI $0.76-0.99))$.
Of 4276 (20\%) subjects prescribed HCQ for 5 years or more, the dose at 5 years of use remained largely unchanged (median $400 \mathrm{mg} /$ day). There was no difference in the proportion of excess dosing between the initial dose and dose at 5 years. Of these subjects, $40 \%$ and $37 \%$ had excess dosing by IBW for the initial dose and at 5 years $(p=0.40) ; 37 \%$ and $33 \%$ had excess dosing by ABW for the initial dose and at 5 years, respectively $(p=0.53)$.

\section{Discussion}

In this UK general population-based cohort, we identified a modest decline in excess HCQ dosing in recent years. While this decline may reflect increased awareness over time of HCQ retinopathy risk, excess HCQ dosing

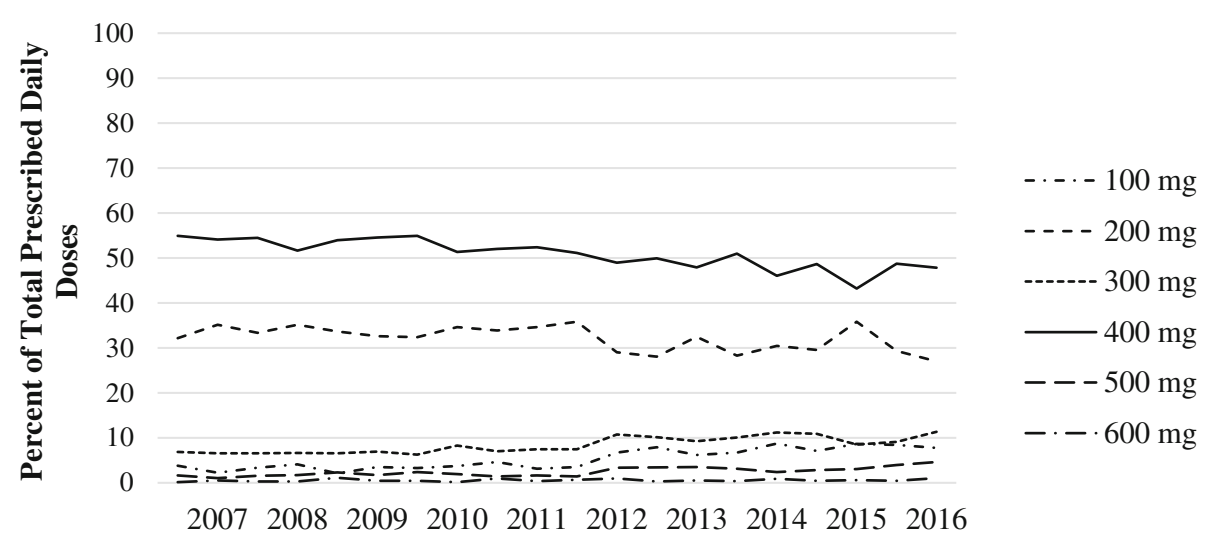

Year

Fig. 2 Incident hydroxychloroquine prescription dose trends. Proportion of incident hydroxychloroquine prescriptions in each dosing category over time, between 2007 and 2016 
remains substantial over the past decade according to prior IBW-based recommendations [2, 16, 17]. Applying the latest ABW-based dosing recommendations [19] also led to a considerable proportion of HCQ excess dosing, including more than 50\% among patients with normal BMI. Overall, the excess dosing using either recommendation was more frequent among women, nearing $50 \%$ using IBW and 38\% using ABW criteria and was less frequent among those with CKD. Moreover, proportions of excess HCQ dosing did not change with long-term use of HCQ (i.e., $>5$ years). This further identifies a target population with the potential for the largest cumulative HCQ exposure and high risk of toxicity [18, 32-34].

To our knowledge, body weight and CKD are the patient factors most associated with risk of HCQ retinopathy [18]. The presence of concomitant CKD was associated with a slightly reduced risk of HCQ excess dosing. This may reflect HCQ dose adjustment in some patients with renal disease. Although there is no clear consensus on appropriate dose reduction in renal insufficiency [35], CKD was associated with more than doubling of the prevalence of HCQ retinopathy in the recent KPNC study [18]. Regardless, in our study found more than $30 \%$ of CKD patients' prescriptions still exceeded recommended doses per the prior or latest guidelines, suggesting potentially considerable room for improvement in this population.

BMI categories had an opposite impact on the risk of excess dosing depending on which weight-based dosing guideline was applied [16, 20]. Following the latest ABW-based guideline, [19] more than $50 \%$ of individuals with normal BMI would have had HCQ excess dosing, compared to $10 \%$ of obese patients. In contrast, using the prior IBW-based guideline [2, 16, 27], 44\% of obese patients and $37 \%$ of normal patients were exposed to excess dosing. This demonstrates the need for provider awareness that the newer guidelines reclassify excess dosing among a greater proportion of individuals with normal body weight.

We also found a higher risk of excess dosing among women, likely because HCQ $400 \mathrm{mg}$ daily, which is the most commonly used dose, falls into the excess ABW dose range and IBW dose range among average-size women in the UK [36-38]. These findings suggest that prescribers in the UK may not have adjusted HCQ dosing based on IBW as recommended by the previous UK RCO guideline [16], particularly among women. It remains to be studied whether the new ophthalmology dosing guidelines will impact future prescribing patterns [20,26]. Additionally, we found that older patients had approximately $20 \%$ higher risk of excess dosing than young patients (Table 2). As this is the first report on the potential impact of aging on excess dosing and its mechanism is not immediately clear, this finding awaits replication by future studies. It is also unknown whether women or older individuals have an increased risk of HCQ retinopathy, which could be correlated with these dosing findings.

A major strength of our study is the use of a large general population database to provide population-level data on HCQ prescribing patterns and thus our findings are likely to be generalizable. However, we were unable to directly address specialty prescriptions, although we found $68 \%$ of HCQ users were referred to rheumatologists and $9 \%$ to dermatologists around the time of first HCQ prescription, and results were similar in these users (data not shown). We focused on prescribed HCQ doses rather than assessing actual dispensed prescriptions or other measures of effective consumed dose of HCQ as our goal for this study was to assess prescribing patterns rather than patient adherence. Finally, our aim was to describe the level of excess HCQ dosing according to the previous and current guidelines; assessing the risk of retinal toxicity was beyond the scope of the current study. As the latest guideline change [20] has been largely based on the single large recent KPNC study [18], further data, particularly prospective evidence, are needed to accurately establish the risk of HCQ retinopathy and risk factors. We do not have sufficient patient-level clinical data to determine the clinical reasoning behind "excess" dosing. To that end, future studies should also address whether reducing HCQ dosing in many patients, following the existing ophthalmology guidelines, will retain the efficacy of this medication.

\section{Conclusions}

In conclusion, this UK general population-based study found that according to previous and latest ophthalmology society guidelines, excess HCQ dosing is substantial, despite a modest decline over recent years. Female patients more often receive an excess HCQ dose according to these guidelines, and a similarly considerable proportion of long-term HCQ users also experience excess HCQ dosing. Over half of normal BMI individuals were excess-dosed per the latest guidelines; however, BMI had a noticeably opposite impact on the risk of excess dosing between the prior and latest weight-based guidelines. This implies the potential need to reduce dosing in many patients but also calls for further research to establish unifying, evidence-based safe-dosing strategies, balancing retinopathy risk and treatment efficacy.

\section{Additional file}

Additional file 1: Figure S1. Overall hydroxychloroquine prescription dose trends. (DOCX $17 \mathrm{~kb}$ )

\section{Acknowledgements}

Preliminary findings from our research have been presented at the 2017 American College of Rheumatology Annual Meeting. 


\section{Funding}

This project was supported in part by the Ruth L. Kirschstein Institutional National Research Service Award T32-AR-007258, National Institutes of Health NIH Grant P60-AR-047785.

\section{Availability of data and materials}

The data that support the findings of this study are available from The Health Improvement Network but restrictions apply to the availability of these data, which were used under license for the current study, and so are not publicly available. Data are however available from the authors upon reasonable request and with permission of The Health Improvement Network.

\section{Authors' contributions}

AMJ, RBM, YZ, and HKC designed the study, interpreted the data, and drafted the manuscript. NL and SKR performed the data analysis and contributed to study design and data interpretation. LHY contributed to study design and revised the manuscript. KHC, RRG, SSL, JME, AEC, MU, AA, $\mathrm{CA}$, and MP also contributed to interpretation of the data and revised the manuscript critically for important intellectual content. All authors read and reviewed the final manuscript

\section{Ethics approval and consent to participate}

This study was approved by the Partners Human Research Committee, protocol number 2017P000399. Informed consent was waived.

\section{Competing interests}

AEC, UCB; MU, UCB; AA, Exagen; MP, Anthera Inc., Glaxo Smith Kline, EMD Serono, Eli Lilly and Company, Bristol Meyer Squibb, Amgen, United Rheumatology, Global Academy, Exagen, HKC, Selecta, Horizon, AstraZeneca. The other authors have declared no competing interests.

\section{Publisher's Note}

Springer Nature remains neutral with regard to jurisdictional claims in published maps and institutional affiliations.

\section{Author details}

${ }^{1}$ Division of Rheumatology, Allergy, and Immunology, Department of Medicine, Massachusetts General Hospital, Harvard Medical School, 55 Fruit Street, Bulfinch 165, Boston, MA 02114, USA. ²Department of Ophthalmology, Kaiser Permanente, Redwood City, CA, USA. ${ }^{3}$ Department of Ophthalmology, Massachusetts Eye and Ear Infirmary, Harvard Medical School, Boston, MA USA. ${ }^{4}$ Division of Rheumatology, Immunology, and Allergy, Brigham and Women's Hospital, Harvard Medical School, Boston, MA, USA. ${ }^{5}$ Rheumatology Division, Feinberg School of Medicine, Northwestern University, Chicago, IL, USA. ${ }^{6}$ Division of Rheumatology, Emory University School of Medicine, Atlanta, GA, USA. ${ }^{7}$ Arthritis Research Canada, Richmond, BC, Canada. ${ }^{8}$ Division of Rheumatology, University of Calgary, Calgary, $\mathrm{AB}$, Canada. ${ }^{9}$ Centre for Prognosis Studies in the Rheumatic Diseases, University of Toronto, Toronto Western Hospital, Toronto, ON, Canada. ${ }^{10}$ Rheumatology, Columbia University College of Physicians \& Surgeons, New York, NY, USA

${ }^{11}$ Autoimmune and Musculoskeletal Disease, The Feinstein Institute for Medical Research, Manhasset, NY, USA. ${ }^{12}$ Division of Rheumatology, Johns Hopkins University School of Medicine, Baltimore, MD, USA

\section{Received: 20 February 2018 Accepted: 25 May 2018}

\section{Published online: 05 July 2018}

\section{References}

1. Ruiz-Irastorza G, Khamashta MA. Hydroxychloroquine: the cornerstone of lupus therapy. Lupus. 2008;17(4):271-3.

2. Bertsias G, loannidis JP, Boletis J, Bombardieri S, Cervera R, Dostal C, Font J, Gilboe IM, Houssiau F, Huizinga T, et al. EULAR recommendations for the management of systemic lupus erythematosus. Report of a task force of the EULAR standing Committee for International Clinical Studies Including Therapeutics. Ann Rheum Dis. 2008;67(2):195-205.

3. A Randomized study of the effect of withdrawing hydroxychloroquine sulfate in systemic lupus erythematosus. The Canadian hydroxychloroquine study group. N Engl J Med. 1991;324:150-4.

4. Alarcon GS, McGwin G, Bertoli AM, Fessler BJ, Calvo-Alen J, Bastian HM, Vila LM, Reveille JD, Group LS. Effect of hydroxychloroquine on the survival of patients with systemic lupus erythematosus: data from LUMINA, a multiethnic US cohort (LUMINA L). Ann Rheum Dis. 2007;66(9):1168-72.

5. Petri M. Use of hydroxychloroquine to prevent thrombosis in systemic lupus erythematosus and in antiphospholipid antibody-positive patients. Curr Rheumatol Rep. 2011;13:77-80.

6. Clowse ME, Magder L, Witter F, Petri M. Hydroxychloroquine in lupus pregnancy. Arthritis Rheum. 2006;54(11):3640-7.

7. Cairoli E, Rebella M, Danese N, Garra V, Borba EF. Hydroxychloroquine reduces low-density lipoprotein cholesterol levels in systemic lupus erythematosus: a longitudinal evaluation of the lipid-lowering effect. Lupus. 2012;21:1178-82.

8. O'Dell JR, Mikuls TR, Taylor TH, Ahluwalia V, Brophy M, Warren SR, Lew RA, Cannella AC, Kunkel G, Phibbs CS, et al. Therapies for active rheumatoid arthritis after methotrexate failure. N Engl J Med. 2013;369(4):307-18.

9. Bansback N, Phibbs CS, Sun H, O'Dell JR, Brophy M, Keystone EC, Leatherman S, Mikuls TR, Anis AH. Triple therapy versus biologic therapy for active rheumatoid arthritis: a cost-effectiveness analysis. Ann Intern Med. 2017;167(1):8-16.

10. Ruiz-Irastorza G, Ramos-Casals M, Brito-Zeron P, Khamashta MA. Clinical efficacy and side effects of antimalarials in systemic lupus erythematosus: a systematic review. Ann Rheum Dis. 2010;69(1):20-8.

11. Costedoat-Chalumeau N, Dunogue B, Leroux G, Morel N, Jallouli M, Le Guern V, Piette JC, Brezin AP, Melles RB, Marmor MF. A critical review of the effects of hydroxychloroquine and chloroquine on the eye. Clin Rev Allergy Immunol. 2015;49(3):317-26.

12. Levy GD, Munz SJ, Paschal J, Cohen HB, Pince KJ, Peterson T. Incidence of hydroxychloroquine retinopathy in 1,207 patients in a large multicenter outpatient practice. Arthritis Rheum. 1997;40(8):1482-6.

13. Mavrikakis I, Sfikakis PP, Mavrikakis E, Rougas K, Nikolaou A, Kostopoulos C, Mavrikakis $\mathrm{M}$. The incidence of irreversible retinal toxicity in patients treated with hydroxychloroquine. Ophthalmology. 2003;110(7):1321-6.

14. Wolfe F, Marmor MF. Rates and predictors of hydroxychloroquine retina toxicity in patients with rheumatoid arthritis and systemic lupus erythematosus. Arthritis Care Res (Hoboken). 2010;62(6):775-84.

15. Ding HJ, Denniston AK, Rao VK, Gordon C. Hydroxychloroquine-related retinal toxicity. Rheumatology. 2016;55(6):957-67.

16. Bourke BJ, Jones S, Rajammal AK, Silman A, Smith R. Hydroxychloroquine and ocular toxicity recommendations on screening. The Royal College of Ophthalmologists in association with The British Society for Rheumatology and the British Association of Dermatologists. 2009.

17. Marmor MF, Kellner U, Lai TY, Lyons JS, Mieler WF. Revised recommendations on screening for chloroquine and hydroxychloroquine retinopathy. Ophthalmology. 2011;118(2):415-22.

18. Melles RB, Marmor MF. The risk of toxic retinopathy in patients on longterm hydroxychloroquine therapy. JAMA Ophthalmol. 2014;132(12):1453-60.

19. Melles RB, Marmor MF. The prevalence of hydroxychloroquine retinopathy and toxic dosing, and the role of the ophthalmologist in reducing both. Am J Ophthalmol. 2016;170:240.

20. Marmor MF, Kellner U, Lai TY, Melles RB, Mieler WF. American Academy of $\mathrm{O}$ : recommendations on screening for chloroquine and hydroxychloroquine retinopathy (2016 revision). Ophthalmology. 2016:123(6):1386-94.

21. Mackenzie AH. Dose refinements in long-term therapy of rheumatoid arthritis with antimalarials. American Journal of Medicine. 1983:75:40-5.

22. Mavrikakis I, Sfikakis PP, Mavrikakis E, Rougas K, Nikolaou A, Kostopoulos C, Mavrikakis $M$. The incidence of irreversible retinal toxicity in patients treated with hydroxychloroquine: a reappraisal. Ophthalmology. 2003;110(7):1321-6.

23. Marmor MF. Hydroxychloroquine screening alert: change is in the wind. Ophthalmic Surg Lasers Imaging Retina. 2017;48(2):96-8.

24. Kim JE, Marmor MF. Update on screening recommendations for hydroxychloroquine retinopathy. JAMA Ophthalmol. 2016;134(7):849.

25. Tucker WR, Galloway J, Walsh S. The gathering storm: hydroxychloroquine retinopathy screening in the U.K. Br J Dermatol. 2017;176(6):1420-1.

26. Gonzalez-Suarez ML, Contreras G. Lower kidney allograft survival in AfricanAmericans compared to Hispanic-Americans with lupus. Lupus. 2017: https://doi.org/10.1177/0961203317699287.

27. Marmor MF, Carr RE, Easterbrook M, Farjo AA, Mieler WF. Recommendations on screening for chloroquine and hydroxychloroquine retinopathy: a report by the American Academy of ophthalmology. Opthamology. 2002;109(7):1377-82.

28. Blak BT, et al. Generalisability of the health improvement network (THIN) database: demographics, chronic disease prevalence and mortality rates. Inform Prim Care. 2011;19(4):251-5. 
29. Plaquenil (hydroxychloroquine) [product mongraph]. Laval, Quebec, Canada: Sanofi-aventis Canada; 2018.

30. Devine B. Case number 25: gentamicin therapy. Drug Intell Clin Pharm. 1974;8:650-5. FDB Solutions: Multilex. https://www.fdbhealth.co.uk/ solutions/multilex. (Accessed date April 2017).

31. Rod NH, Lange T, Andersen I, Marott JL, Diderichsen F. Additive interaction in survival analysis: use of the additive hazards model. Epidemiology. 2012 23(5):733-7.

32. Eo DR, Lee MG, Ham DI, Kang SW, Lee J, Cha HS, Koh E, Kim SJ. Frequency and clinical characteristics of hydroxychloroquine retinopathy in Korean patients with rheumatologic diseases. J Korean Med Sci. 2017;32(3):522-7.

33. Kobak S, Deveci H. Retinopathy due to antimalarial drugs in patients with connective tissue diseases: are they so innocent? A single center retrospective study. Int J Rheum Dis. 2010;13(3)::11-5.

34. Jorge A, Rai S, Choi HK. The risk of hydroxychloroquine toxic retinopathy and its risk factors in the treatment of rheumatic diseases: a systematic review [abstract]. Arthritis Rheum. 2017;69(Suppl 10)

35. Durcan L, Clarke WA, Magder LS, Petri M. Hydroxychloroquine blood levels in systemic lupus erythematosus: clarifying dosing controversies and improving adherence. J Rheumatol. 2015;42(11):2092-7.

36. Statistics on Obesity, Physical Activity and Diet- England, 2016. NHS Digital; 2016. http://digital.nhs.uk/data-and-information/publications/statistical/ statistics-on-obesity-physical-activity-and-diet/statistics-on-obesity-physicalactivity-and-diet-england-2016

37. Walvick MD, Walvick MP, Tongson E, Ngo CH. Hydroxychloroquine: lean body weight dosing. Ophthalmology. 2011;118(10):2100. author reply 2101

38. Browning DJ, Lee C, Rotberg D. The impact of different algorithms for ideal body weight on screening for hydroxychloroquine retinopathy in women. Clin Ophthalmol. 2014;8:1401-7.

\section{Ready to submit your research? Choose BMC and benefit from:}

- fast, convenient online submission

- thorough peer review by experienced researchers in your field

- rapid publication on acceptance

- support for research data, including large and complex data types

- gold Open Access which fosters wider collaboration and increased citations

- maximum visibility for your research: over $100 \mathrm{M}$ website views per year

At BMC, research is always in progress.

Learn more biomedcentral.com/submissions 